\title{
Efficacy of Super Slick Elastomeric Modules in reducing Friction during Sliding: A Comparative in vitro Study
}

\author{
${ }^{1}$ Sadhiq Khan Pattan, ${ }^{2}$ Revathi Peddu, ${ }^{3}$ Shyam Kumar Bandaru, ${ }^{4}$ Devikanth Lanka \\ ${ }^{5}$ Kalyani Mallavarapu, ${ }^{6}$ Azher Banu Pathan
}

\begin{abstract}
Aim: To evaluate and compare the frictional resistance produced by Super Slick modules during sliding with four different types of brackets and four ligature types both in conventional and figure-of-8 ligation method with saliva as lubricant.
\end{abstract}

Materials and methods: The frictional resistance was evaluated by using four different ligatures on 0.019 " $\times 0.025$ " stainless steel (SS) archwires using four different brackets using an universal testing machine with unstimulated saliva as a lubricant. Mean and SD values were calculated. Data was statistically analyzed using analysis of variance ANOVA with post hoc test

Results: The results showed that self-ligating brackets produced least frictional forces. Among all other tested combinations, Teflon-coated SS ligatures in ceramic with metal slot brackets produced least coefficient of static and kinetic friction and full ceramic brackets ligated with Super Slick elastomeric modules demonstrated the highest, with other combinations falling in between.

Conclusion: Super Slick elastomeric modules, produced highest coefficient of both static and kinetic friction with the conventional and figure-of-8 ligation technique even in wet conditions using natural fresh human saliva.

Clinical significance: Both static and kinetic frictional resistance play an important role during sliding mechanics. Various factors have been attributed for friction. However, bracket type, archwire material, type of ligature and method of ligation are important variables. Recently polymeric coated slick elastomeric modules were introduced with the claim that they produce very low frictional forces in wet condition. Contrary to the claim made by the manufacturers of Super Slick elastomeric modules, they produced highest coefficient of both static and kinetic friction with the conventional and figure-of-8 ligation technique.

Keywords: Self-ligating brackets, Super Slick elastomeric modules, Teflon-coated stainless steel ligatures, Conventional ligation and figure-of-8 ligation.

\footnotetext{
${ }^{1,4,6}$ Senior Lecturer, ${ }^{2} \mathrm{Head},{ }^{3}$ Professor, ${ }^{5}$ Reader

${ }^{1-5}$ Department of Orthodontics, Sibar Institute of Dental Sciences, Guntur, Andhra Pradesh, India

${ }^{6}$ Department of Conservative Dentistry and Endodontics, Sibar Institute of Dental Sciences, Guntur, Andhra Pradesh, India

Corresponding Author: Sadhiq Khan Pattan, Senior Lecturer, Department of Orthodontics, Sibar Institute of Dental Sciences, Guntur, Andhra Pradesh, India, Phone: 9948281228 e-mail: sadhiqkhanpattan03@yahoo.com
}

How to cite this article: Pattan SK, Peddu R, Bandaru SK, Lanka D, Mallavarapu K, Pathan AB. Efficacy of Super Slick Elastomeric Modules in reducing Friction during Sliding: A Comparative in vitro Study. J Contemp Dent Pract. 2014; 15(5):543-551.

\section{Source of support: Nil}

Conflict of interest: None declared

\section{INTRODUCTION}

Space closure and canine retraction in sliding mechanics involve a relative motion of bracket over wire. Excessive amounts of bracket/wire friction may result in loss of anchorage or binding accompanied by little or no tooth movement. The preferred wire material for moving a tooth relative to the wire would be one that produces the least amount of friction at the bracket/wire interface. ${ }^{1}$

Many factors that affect friction have been investigated, such as wire alloy composition, wire dimensions, bracket material, bracket width and test variables, including bracket/ archwire angulation, dry and wet conditions and ligation material and methods. ${ }^{2}$ Stainless steel (SS) brackets have been used for decades with highly successful clinical results. Increased esthetic demands of the patients led to the introduction of tooth-colored brackets like plastic and ceramic brackets. ${ }^{3}$ Self-ligating brackets have gained popularity in recent years, the primary advantage being the reduced friction. ${ }^{4}$

Loosely tied stainless steel ligatures are generally thought to generate less friction than standard elastomeric ligatures. ${ }^{2}$ Saliva serves as an excellent lubricant with elastic ligatures and the small movements of the teeth in function provide a 'walking' effect that allows the arch to move much more easily over a period of time than it might at the time of initial loading. ${ }^{5}$ Few studies have been investigated for the interaction between the physical characteristics of the ligation method and frictional forces. Ligating archwires with elastomeric ligatures in a 'figure-of- 8 ' pattern increases resistance to sliding mechanics by a factor of 70 to $220 \%$, depending on wire dimension. ${ }^{6}$

New polymeric-coated slick elastomeric modules incorporating metafasix technology (TP orthodontics) has recently been introduced. ${ }^{2}$ They claimed that these modules become extremely slippery when wet or moistened in the oral environment and the highly lubricious surface has proven to 


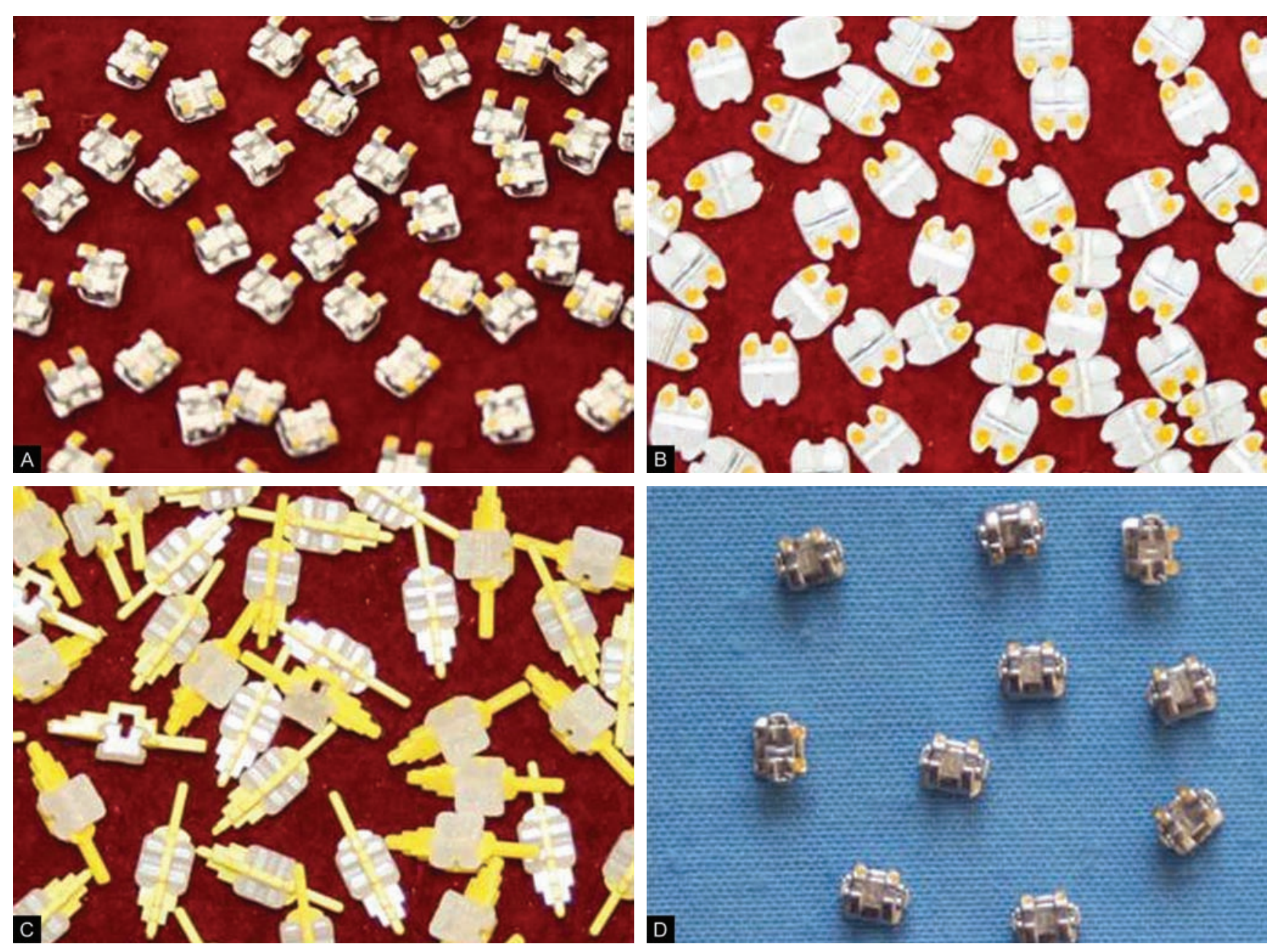

Figs 1A to D: Orthodontic brackets used in the study

reduce friction by more than $70 \%$ during orthodontic treatment and is more economical than expensive selfl-igating brackets.

The slick coating appeared to be resistant to abrasion in a simulated clinical setting. ${ }^{7}$ Hence, the present study was taken up to evaluate the frictional resistance of Super Slick elastomeric modules during sliding and to compare the frictional resistance of Super Slick modules with three other types of ligatures, both in conventional and figure-of- 8 ligation method with saliva as lubricant.

\section{MATERIALS AND METHODS}

Four types of $0.022 " \times 0.028$ " standard maxillary right first premolar MBT brackets with zero degree tip and $-7^{\circ}$ torque were used (Figs 1A to D).

The sample for this in vitro study included 80 victory twin metal brackets (SS), clarity metal-reinforced ceramic brackets (CMS), transcend full ceramic (FC) brackets and 10 smartclip self-ligating brackets (SLB). All brackets belong to 3M Unitek, Monorovia, CA, USA.

The elastic modules (Figs 2A and B) and ligatures (Figs $3 \mathrm{~A}$ and $\mathrm{B}$ ) compared were Super Slick elastomeric modules (TP Orthodontics, La-Porte, Ind) and Gray modules
(3M Unitek, Monorovia, CA, USA), Stainless steel 0.009" ligatures (Modern orthodontics, US) and Teflon coated 0.012 SS ligatures (Ortho organizers). 0.019" × 0.025" SS (Libral Traders, New Delhi) straight length wires were used to test the brackets (Fig. 4).

\section{METHODS}

Perspex blocks 250 were obtained (Figs 5A and B) and brackets were mounted on the blocks using epoxy resin. Fifty straight lengths of SS wires each measuring $350 \mathrm{~mm}$ were obtained and each length was cut into 5 pieces of $60 \mathrm{~mm}$ each. Thus, 250 pieces of SS wires were obtained.

On each $60 \mathrm{~mm}$ of $0.019 " \times 0.025$ " SS wire length of the archwires another marking was made at $10 \mathrm{~mm}$ distance from one end of the archwires and a right angle bend was made using tweed plier as shown in figure. In addition to the 250 blocks another block of same dimensions was prepared in such a manner that a $20 \mathrm{~mm}$ length of orthodontic tubing, with a $0.8 \mathrm{~mm}$ internal diameter was secured to the block with self-cure acrylic resin. The short end of the archwire $(10 \mathrm{~mm}$ ) was inserted into the tubing and the other end (free end) was placed in the bracket slot (Fig. 6). 

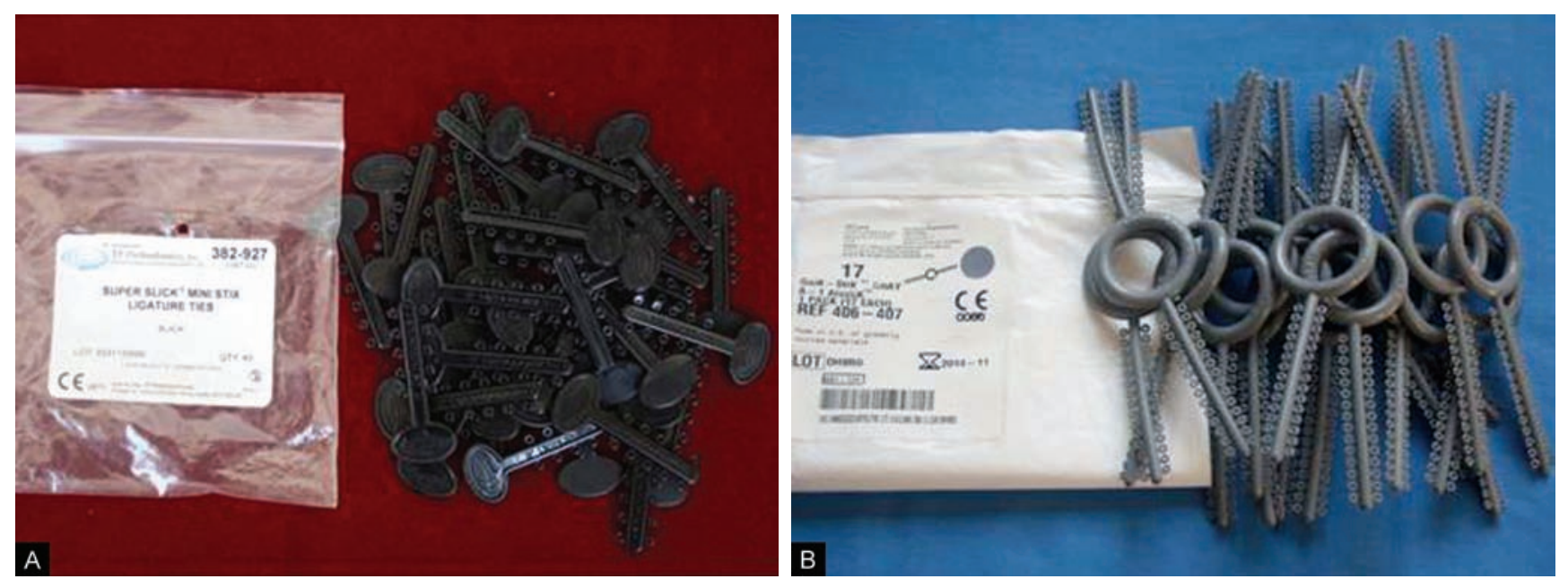

Figs $2 \mathrm{~A}$ and B: Elastomeric modules used in the study
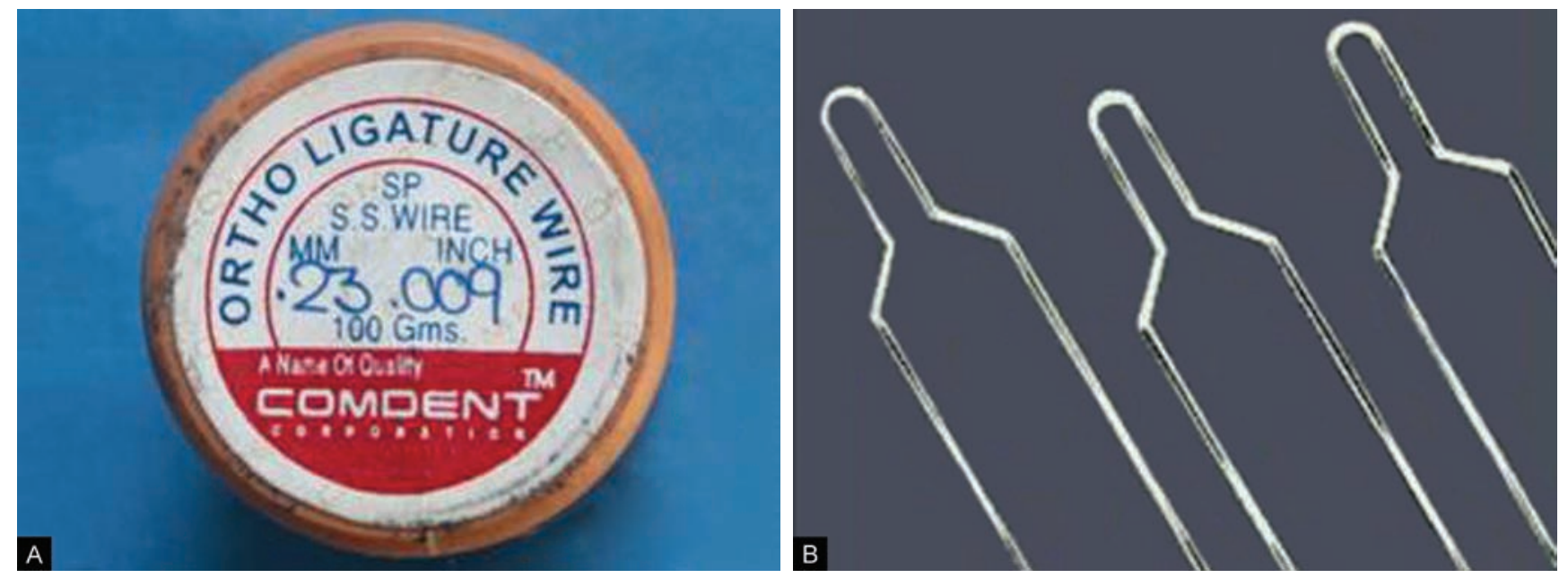

Figs 3A and B: (A) Stainless steel 0.009" ligatures and (B) Teflon-coated 0.012" SS ligatures

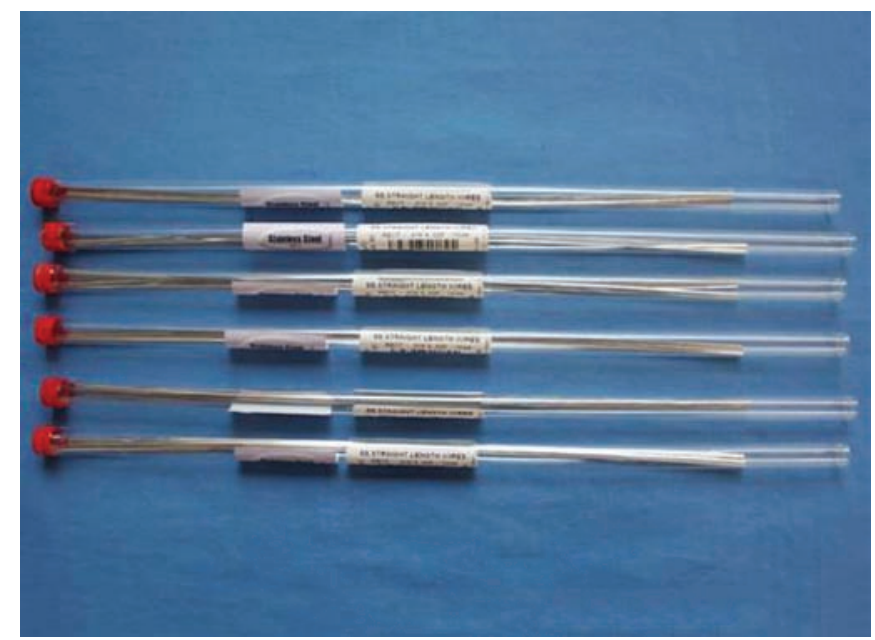

Fig. 4: Stainless steel wires $\left(0.019^{\prime \prime} \times 0.025^{\prime \prime}\right)$

Except the self-ligating brackets all brackets and wires were held together with either one of ligature types, i.e. Gray, Super Slick elastomeric modules, Teflon-coated SS ligature and 0.009" SS ligature. Ligation was done in both conventional and figure-of- 8 pattern, 250 samples were made with different bracket arch wire combinations using different ligatures and different ligation methods.
An universal testing machine (INSTRON model No $4467 \mathrm{H}$ 2066) with a $5 \mathrm{~kg}$ load was used to measure the frictional resistance (Fig. 7). All the archwires and brackets were washed in 95\% ethanol and air dried prior to testing. Tests were conducted in the presence of fresh human saliva, which was obtained without stimulation and was dripped onto the bracket wire junction at a rate of $1 \mathrm{ml} / \mathrm{min}$ from a syringe (Fig. 8). The cross head speed was set at $5 \mathrm{~mm} / \mathrm{min}$. Each bracket and arch wire combination was tested 10 times with each ligature type. Each combination was tested only once to eliminate the influence of wear and a total of 250 specimens were tested.

The system of acquisition measured the force values (Newtons) needed to move the bracket along the wire and the values were recorded by a computer. The static friction was calculated at the initial peak of movement. The dynamic friction was calculated as average of 10 acquisitions made at a distance of $20 \mathrm{~mm}$ each, after the peak.

\section{Statistical Analysis}

All the analysis was carried out using SPSS version 17 (SPSS Inc, Chicago, Illinois, USA). Descriptive statistics were 


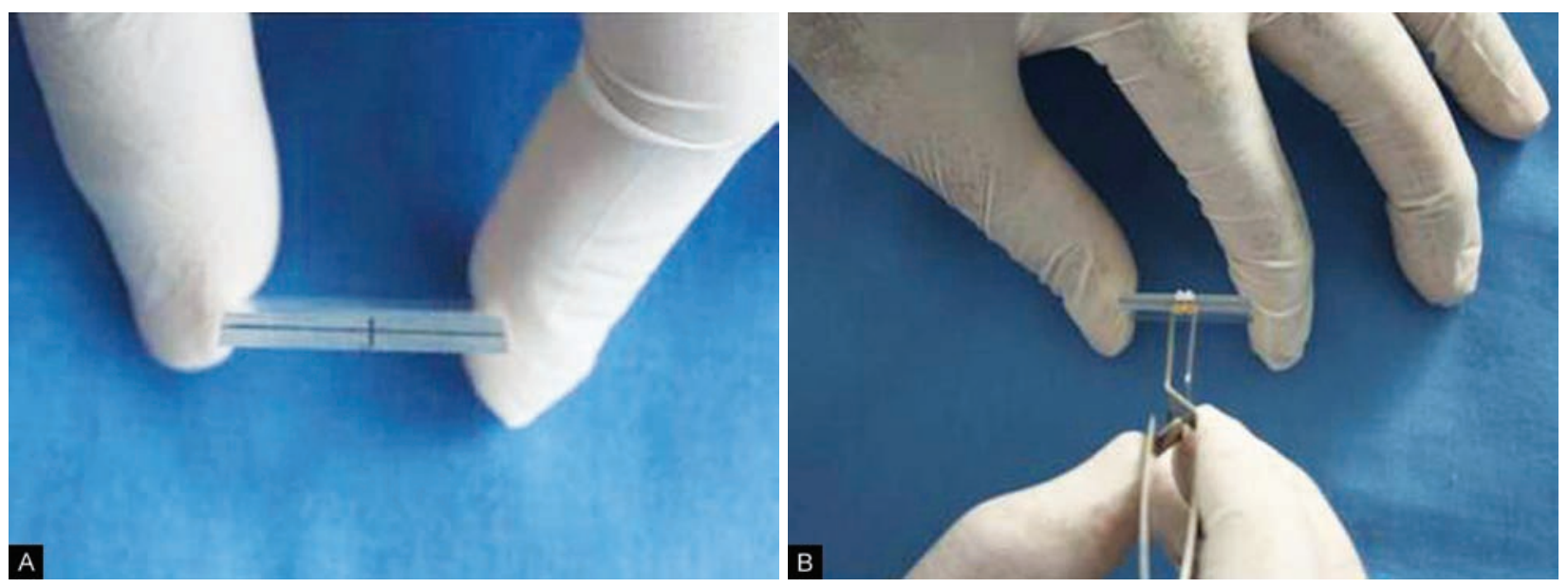

Figs $5 \mathrm{~A}$ and $\mathrm{B}$ : Positioning the bracket

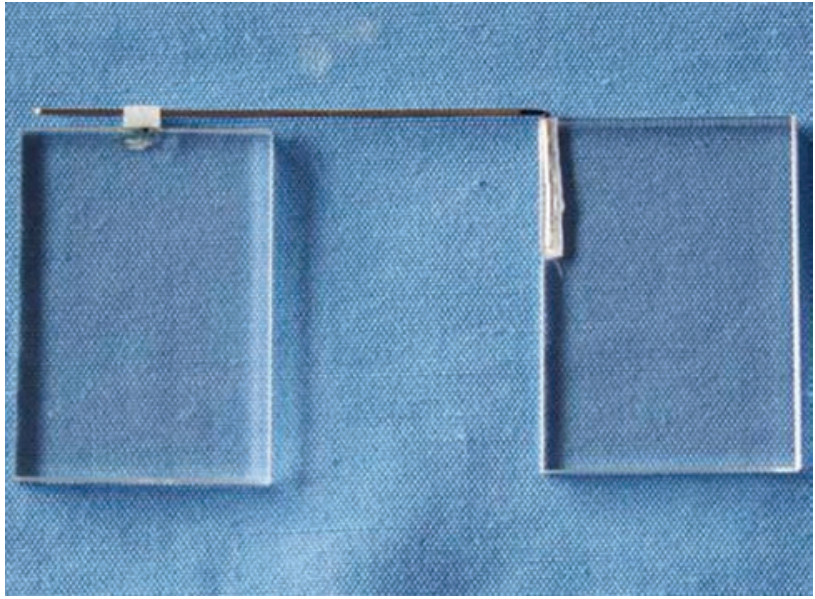

Fig. 6: Upper and lower Perspex blocks with archwire in place

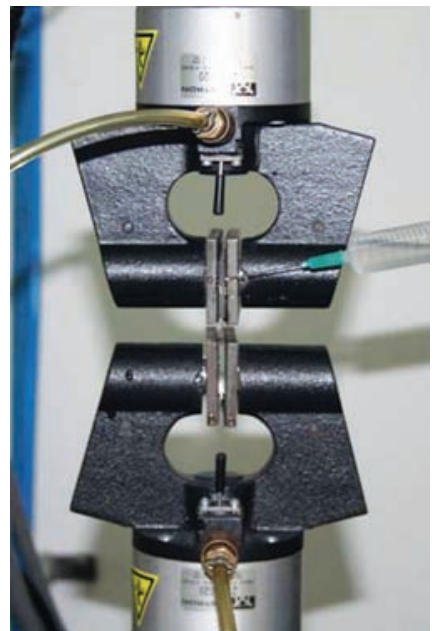

Fig. 8: Dripping of saliva

calculated for each group and presented as mean, standard deviation and analysis of variance (ANOVA) followed by post hoc LSD test. A p-value of $<0.05$ considered statistically significant.

\section{RESULTS}

Results are presented in Tables 1 through 4 . Tables 1 and 3 shows groupwise comparisons of static and kinetic friction

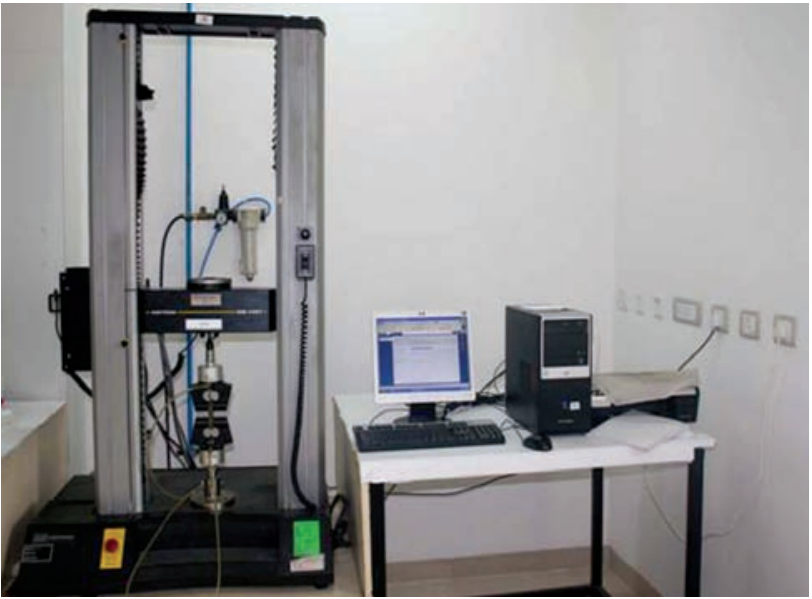

Fig. 7: Universal testing machine

by means of ANOVA with post hoc test respectively. Tables 2 and 4 depicts intergroup comparisons of static and kinetic friction by means of post hoc test respectively.

\section{Static Coefficient of Friction}

The results showed that self-ligating brackets produced lowest coefficient of static friction compared to any other ligature - bracket combinations (Tables 1 and 2). Static friction produced by SS, ceramic with metal slot and full ceramic brackets with different types of ligatures in conventional method of ligation showed that Teflon-coated SS ligatures produced the lowest coefficient of friction.

'With figure-of-8 ligation static coefficient of friction was lowest with SS ligatures in SS brackets (0.06). Whereas Teflon coated SS ligatures in figure-of-8 ligation with ceramic with metal slot and full ceramic brackets showed lowest frictional resistance. With all the ligatures, figure-of- 8 ligation method generated higher coefficient of static friction than with the conventional ligation method as shown in Tables 1 and 2.'

Irrespective of the method of ligation Teflon-coated SS ligatures produced lower static as well as kinetic coefficient 
Table 1: Groupwise comparisons of static coefficient of friction by analysis of variance with post hoc least significant difference test

\begin{tabular}{|c|c|c|c|c|c|c|}
\hline Bracket & & $N$ & Mean & $S D$ & $p$-value & Post hoc test \\
\hline \multirow{9}{*}{$\begin{array}{l}\text { Stainless steel } \\
\text { (SS) }\end{array}$} & 1. SS ligature (conventional) & 10 & 0.05 & 0.03 & $<0.001$ & $1>2,3,5,6,7,9$ \\
\hline & 2. SS ligature (Fig. 8) & 10 & 0.06 & 0.05 & & $2>9$ \\
\hline & 3. Gray (conventional) & 10 & 0.11 & 0.09 & & $3>2,5,6,9$ \\
\hline & 4. Gray (Fig. 8) & 10 & 0.20 & 0.05 & & $4>3,5,6,7$ \\
\hline & 5. Teflon (conventional) & 10 & 0.07 & 0.04 & & $5>9$ \\
\hline & 6. Teflon (Fig. 8) & 10 & 0.06 & 0.05 & & $6>9$ \\
\hline & 7. Slick (conventional) & 10 & 0.15 & 0.05 & & $7>2,3,5,6,9$ \\
\hline & 8. Slick (Fig. 8) & 10 & 0.21 & 0.03 & & $8>2,3,5,6,7,9$ \\
\hline & 9. Self ligating & 10 & 0.00 & 0.00 & & \\
\hline \multirow{8}{*}{$\begin{array}{l}\text { Ceramic with } \\
\text { metal slot }\end{array}$} & 1. SS ligature (conventional) & 10 & 0.04 & 0.01 & $<0.001$ & \\
\hline & 2. SS ligature (Fig. 8) & 10 & 0.07 & 0.05 & & $2>1,5,6$ \\
\hline & 3. Gray (conventional) & 10 & 0.19 & 0.03 & & $3>1,5,6$ \\
\hline & 4. Gray (Fig. 8) & 10 & 0.22 & 0.07 & & $4>1,2,3,5,6,7$ \\
\hline & 5. Teflon (conventional) & 10 & 0.04 & 0.02 & & \\
\hline & 6. Teflon (Fig. 8) & 10 & 0.09 & 0.01 & & \\
\hline & 7. Slick (conventional) & 10 & 0.13 & 0.04 & & $7>1,5,6$ \\
\hline & 8. Slick (Fig. 8) & 10 & 0.24 & 0.09 & & $8>1,2,3,5,6,7$ \\
\hline \multirow[t]{8}{*}{ Full ceramic } & 1. SS ligature (conventional) & 10 & 0.19 & 0.08 & $<0.001$ & $1>5,6$ \\
\hline & 2. SS ligature (Fig. 8) & 10 & 0.11 & 0.07 & & \\
\hline & 3. Gray (conventional) & 10 & 0.17 & 0.04 & & $3>5,6$ \\
\hline & 4. Gray (Fig. 8) & 10 & 0.16 & 0.06 & & $4>2,5,6$ \\
\hline & 5. Teflon (conventional) & 10 & 0.07 & 0.02 & & \\
\hline & 6. Teflon (Fig. 8) & 10 & 0.08 & 0.03 & & \\
\hline & 7. Slick (conventional) & 10 & 0.13 & 0.04 & & \\
\hline & 8. Slick (Fig. 8) & 10 & 0.24 & 0.04 & & $8>1,2,3,4,5,6,7$ \\
\hline
\end{tabular}

SD: Standard deviation

of friction than other ligatures, while Super Slick elastomeric modules produced highest coefficient of static friction.

\section{Dynamic Coefficient of Friction}

With a mean of 0.0059 self-ligating brackets produced lowest coefficient of static friction compared to any other ligaturebracket combinations. Dynamic friction produced by SS brackets with different types of ligatures in conventional method of ligation showed that Teflon-coated SS ligatures showed the lowest coefficient of friction (Mean $=0.0462)$ as shown in Tables 3 and 4.

With figure-of-8 ligation, dynamic coefficient of friction was lowest with SS brackets ligated with SS ligatures in figure-of-8 ligation, method (0.0542). Whereas, Tefloncoated stainless SS in figure-of-8 ligation with ceramic with metal slot and full ceramic brackets showed lowest frictional resistance.

\section{DISCUSSION}

When sliding mechanics are used, friction occurs at the bracket-wire interface. Some of the applied force is dissipated as friction and the remainder is transferred to supporting structures of the tooth to mediate tooth movement. Therefore, maximum biological tissue response occurs only when the applied force is of sufficient magnitude to adequately overcome friction and lie within the optimum range of forces necessary for movement of the tooth.

A large number of variables such as bracket (material, slot width and depth), arch wire (material and cross-section shape and size), ligation of archwire to bracket (ligatures, elastomerics and method of ligation), biological (saliva, plaque and corrosion) exist that can directly or indirectly contribute to the frictional force levels between the bracket and the wire.

Orthodontists today have a multitude of options when it comes to selecting a bracket. In our study, SS brackets produced the lowest statistically significant frictional force values ( $\mathrm{p}<0.001)$ in all tested combinations, which is in concurrence with the data published in previous studies. And the frictional values of ceramic bracket with meta slot were greater than SS brackets, but full ceramic bracket showed the greatest statistically significant frictional resistance values $(\mathrm{p}<0.001)$ in all tested combinations, which is in line with the studies conducted by Clarice Nishio da Motta AF, Elias $\mathrm{CN}$, Mucha $\mathrm{JN}^{8}$ and HS Griffiths, M Sherriff and AJ Ireland. ${ }^{9}$

Self-ligating brackets are resurging from the early 20th century. These brackets provide considerably less frictional resistance to sliding than conventionally ligated brackets. ${ }^{10}$ Passive self-ligating brackets (SmartClip) were tested for frictional evaluation and these considered almost as control group. In the present study self-ligating brackets produced 
Table 2: Intergroup comparisons of static coefficient of friction by post hoc test

\begin{tabular}{|c|c|c|c|c|c|c|c|}
\hline Bracket & Technique & & $N$ & Mean & $S D$ & $p$-value & Post hoc test \\
\hline \multirow{8}{*}{$\begin{array}{l}\text { Stainless steel } \\
\text { (SS) }\end{array}$} & \multirow[t]{4}{*}{ Conventional } & 1. SS ligature (conventional) & 10 & 0.05 & 0.03 & \multirow[t]{4}{*}{$<0.001$} & $1>2,3,4$ \\
\hline & & 2. Gray (conventional) & 10 & 0.11 & 0.04 & & $2>3$ \\
\hline & & 3. Teflon (conventional) & 10 & 0.05 & 0.04 & & \\
\hline & & 4. Slick (conventional) & 10 & 0.15 & 0.05 & & \\
\hline & \multirow[t]{4}{*}{ Fig. 8} & 1. SS ligature (Fig. 8) & 10 & 0.06 & 0.05 & \multirow[t]{4}{*}{$<0.001$} & $2>1,3$ \\
\hline & & 2. Gray (Fig. 8) & 10 & 0.20 & 0.05 & & \\
\hline & & 3. Teflon (Fig. 8) & 10 & 0.06 & 0.05 & & \\
\hline & & 4. Slick (Fig. 8) & 10 & 0.21 & 0.03 & & $4>1,3$ \\
\hline \multirow{8}{*}{$\begin{array}{l}\text { Ceramic with } \\
\text { metal slot }\end{array}$} & \multirow[t]{4}{*}{ Conventional } & 1. SS ligature (conventional) & 10 & 0.04 & 0.01 & \multirow[t]{4}{*}{$<0.001$} & \\
\hline & & 2. Gray (conventional) & 10 & 0.12 & 0.03 & & $2>1,3$ \\
\hline & & 3. Teflon (conventional) & 10 & 0.04 & 0.02 & & \\
\hline & & 4. Slick (conventional) & 10 & 0.12 & 0.04 & & $4>1,3$ \\
\hline & \multirow[t]{4}{*}{ Fig. 8} & 1. SS ligature (Fig. 8) & 10 & 0.09 & 0.05 & \multirow[t]{4}{*}{$<0.001$} & \\
\hline & & 2. Gray (Fig. 8) & 10 & 0.22 & 0.07 & & $2>1,3$ \\
\hline & & 3. Teflon (Fig. 8) & 10 & 0.04 & 0.01 & & \\
\hline & & 4. Slick (Fig. 8) & 10 & 0.24 & 0.09 & & $4>1,3$ \\
\hline \multirow[t]{8}{*}{ Full ceramic } & \multirow[t]{4}{*}{ Conventional } & 1. SS ligature (conventional) & 10 & 0.13 & 0.08 & \multirow[t]{4}{*}{0.016} & $1>3$ \\
\hline & & 2. Gray (conventional) & 10 & 0.14 & 0.04 & & $2>3,4$ \\
\hline & & 3. Teflon (conventional) & 10 & 0.07 & 0.02 & & \\
\hline & & 4. Slick (conventional) & 10 & 0.13 & 0.04 & & $4>3$ \\
\hline & \multirow[t]{4}{*}{ Fig. 8} & 1. SS ligature (Fig. 8) & 10 & 0.11 & 0.07 & \multirow[t]{4}{*}{$<0.001$} & \\
\hline & & 2. Gray (Fig. 8) & 10 & 0.16 & 0.06 & & $2>1,3$ \\
\hline & & 3. Teflon (Fig. 8) & 10 & 0.08 & 0.03 & & \\
\hline & & 4. Slick (Fig. 8) & 10 & 0.24 & 0.04 & & $4>1,2,3$ \\
\hline
\end{tabular}

SD: Standard deviation

Table 3: Groupwise comparisons of dynamic coefficient of friction by analysis of variance with post hoc least significant difference test

\begin{tabular}{|c|c|c|c|c|c|c|}
\hline Bracket & & $N$ & Mean & $S D$ & $p$-value & Post hoc test \\
\hline \multirow{9}{*}{$\begin{array}{l}\text { Stainless steel } \\
\text { (SS) }\end{array}$} & 1. SS ligature (conventional) & 10 & 0.06 & 0.02 & \multirow[t]{9}{*}{$<0.001$} & $1>9$ \\
\hline & 2. SS ligature (Fig. 8) & 10 & 0.05 & 0.05 & & $2>9$ \\
\hline & 3. Gray (conventional) & 10 & 0.09 & 0.01 & & $3>2,5,9$ \\
\hline & 4. Gray (Fig. 8) & 10 & 0.17 & 0.04 & & $4>1,2,3,5,6,7,9$ \\
\hline & 5. Teflon (conventional) & 10 & 0.05 & 0.04 & & $5>9$ \\
\hline & 6. Teflon (Fig. 8) & 10 & 0.06 & 0.05 & & $6>9$ \\
\hline & 7. Slick (conventional) & 10 & 0.14 & 0.02 & & $7>1,2,3,6,8,9$ \\
\hline & 8. Slick (Fig. 8) & 10 & 0.19 & 0.01 & & $8>1,2,3,6,7,9$ \\
\hline & 9. Self ligating & 10 & 0.01 & 0.00 & & \\
\hline \multirow{8}{*}{$\begin{array}{l}\text { Ceramic with } \\
\text { metal slot }\end{array}$} & 1. SS ligature (conventional) & 10 & 0.04 & 0.01 & \multirow[t]{8}{*}{$<0.001$} & \\
\hline & 2. SS ligature (Fig. 8) & 10 & 0.08 & 0.04 & & $2>1,5,6$ \\
\hline & 3. Gray (conventional) & 10 & 0.09 & 0.01 & & $3>1,5,6$ \\
\hline & 4. Gray (Fig. 8) & 10 & 0.16 & 0.05 & & $4>1,2,3,5,6,7$ \\
\hline & 5. Teflon (conventional) & 10 & 0.03 & 0.02 & & \\
\hline & 6. Teflon (Fig. 8) & 10 & 0.04 & 0.01 & & \\
\hline & 7. Slick (conventional) & 10 & 0.11 & 0.03 & & $7>1,5,6$ \\
\hline & 8. Slick (Fig. 8) & 10 & 0.19 & 0.08 & & $8>1,2,3,5,6,7$ \\
\hline \multirow[t]{8}{*}{ Full ceramic } & 1. SS ligature (conventional) & 10 & 0.12 & 0.07 & \multirow[t]{8}{*}{$<0.001$} & $1>5,6$ \\
\hline & 2. SS ligature (Fig. 8) & 10 & 0.09 & 0.05 & & \\
\hline & 3. Gray (conventional) & 10 & 0.09 & 0.02 & & \\
\hline & 4. Gray (Fig. 8) & 10 & 0.13 & 0.05 & & $4>2,5,6$ \\
\hline & 5. Teflon(conventional) & 10 & 0.06 & 0.02 & & \\
\hline & 6. Teflon (Fig. 8) & 10 & 0.07 & 0.03 & & \\
\hline & 7. Slick (conventional) & 10 & 0.11 & 0.04 & & $7>5,6$ \\
\hline & 8. Slick (Fig. 8) & 10 & 0.17 & 0.06 & & $8>1,2,3,5,6,7$ \\
\hline
\end{tabular}

SD: Standard deviation 
Table 4: Intergroup comparisons of dynamic coefficient of friction by post hoc test

\begin{tabular}{|c|c|c|c|c|c|c|c|}
\hline Bracket & Technique & & $N$ & Mean & $S D$ & $p$-value & Post hoc test \\
\hline \multirow[t]{8}{*}{ Stainless steel (SS) } & Conventional & $\begin{array}{l}\text { 1. SS ligature } \\
\text { (conventional) }\end{array}$ & 10 & 0.06 & 0.04 & $<0.001$ & \\
\hline & & 2. Gray (conventional) & 10 & 0.09 & 0.01 & & $2>3$ \\
\hline & & 3. Teflon (conventional) & 10 & 0.05 & 0.04 & & \\
\hline & & 4. Slick (conventional) & 10 & 0.14 & 0.02 & & $4>1,2,3$ \\
\hline & Fig. 8 & 1. SS ligature (Fig. 8) & 10 & 0.05 & 0.05 & $<0.001$ & $2>1,3$ \\
\hline & & 2. Gray (Fig. 8) & 10 & 0.17 & 0.04 & & \\
\hline & & 3. Teflon (Fig. 8) & 10 & 0.06 & 0.05 & & $4>1,3$ \\
\hline & & 4. Slick (Fig. 8) & 10 & 0.19 & 0.01 & & \\
\hline \multirow[t]{8}{*}{$\begin{array}{l}\text { Ceramic with metal } \\
\text { slot }\end{array}$} & Conventional & $\begin{array}{l}\text { 1. SS ligature } \\
\text { (conventional) }\end{array}$ & 10 & 0.04 & 0.01 & $<0.001$ & \\
\hline & & 2. Gray (conventional) & 10 & 0.09 & 0.01 & & $2>1,3$ \\
\hline & & 3. Teflon (conventional) & 10 & 0.03 & 0.02 & & \\
\hline & & 4. Slick (conventional) & 10 & 0.11 & 0.03 & & $4>1,2,3$ \\
\hline & Fig. 8 & 1. SS ligature (Fig. 8) & 10 & 0.08 & 0.04 & $<0.001$ & \\
\hline & & 2. Gray (Fig. 8) & 10 & 0.16 & 0.05 & & $2>1,3$ \\
\hline & & 3. Teflon (Fig. 8) & 10 & 0.04 & 0.01 & & \\
\hline & & 4. Slick (Fig. 8) & 10 & 0.19 & 0.08 & & $4>1,3$ \\
\hline \multirow[t]{8}{*}{ Full ceramic } & Conventional & $\begin{array}{l}\text { 1. SS ligature } \\
\text { (conventional) }\end{array}$ & 10 & 0.12 & 0.07 & 0.026 & $1>3$ \\
\hline & & 2. Gray (conventional) & 10 & 0.09 & 0.01 & & \\
\hline & & 3. Teflon (conventional) & 10 & 0.06 & 0.03 & & \\
\hline & & 4. Slick (conventional) & 10 & 0.11 & 0.04 & & $4>3$ \\
\hline & Fig. 8 & 1. SS (Fig. 8) & 10 & 0.09 & 0.05 & $<0.001$ & \\
\hline & & 2. Gray (Fig. 8) & 10 & 0.19 & 0.05 & & $2>3$ \\
\hline & & 3. Teflon (Fig. 8) & 10 & 0.07 & 0.03 & & \\
\hline & & 4. Slick (Fig. 8) & 10 & 0.18 & 0.06 & & $4>1,3$ \\
\hline
\end{tabular}

SD: Standard deviation

lowest coefficient of static and dynamic friction compared to any other ligature - bracket combinations which is in agreement with RP Kusy ${ }^{11}$ and Shivapuja and Berger. ${ }^{12}$

Except the self-ligating brackets, all brackets and wires were held together with either one of ligature types. Among the four different ligatures, Teflon-coated SS ligatures produced lowest coefficient of both static and kinetic friction followed by SS ligatures, gray elastomeric modules and Super Slick elastomeric modules in ascending order, which is in line with David J.De Franco, Robert E Spiller, JA Von Fraunhofer ${ }^{13}$ and Thaís Gelatti Bortoly. ${ }^{14}$

The results of the present study is in agreement of studies conducted by Max Hain ${ }^{2}$ and B Khamby, D Millett and S Mchugh ${ }^{15}$ who demonstrated that SS ligatures produced the lowest mean frictional forces than elastomeric modules.

In the present study it was found that Super Slick elastomeric ligatures produced greater frictional forces than any ligation material. This finding is supported by Balvinder Khambay, Declan Millett and Siobhan McHugh ${ }^{15}$ and Helen Sylvia Griffiths, Martyn Sherriff and Anthony John Ireland. ${ }^{9}$

The method of archwire ligation would appear to be an important determinant in the generation of friction. The results of the present study indicated that with all the ligatures, figure-of- 8 ligation method generated higher coeffi- cient of static friction than with the conventional ligation method which is in agreement with Max Hain ${ }^{2}$ and Edwards et al. ${ }^{16}$

It has been suggested that saliva or a saliva substitute serves as an excellent lubricant in the sliding of the bracket along the wire ${ }^{5,17}$ and it decreases the friction. ${ }^{18}$ The effects of saliva on friction are controversial, because investigations carried out under dry conditions or with the addition of human or artificial saliva or water have produced conflicting results.

Kusy ${ }^{17}$ stated that experiments conducted in artificial saliva were invalid because it is no substitute for human saliva. Kevin L Baker, Lewis G Neiberg, Allan D Weimer and Milford Hanna ${ }^{18}$ determined that the introduction of saliva substitute provided a significant reduction in force values. The present study was conducted in the presence of fresh human saliva, which was obtained without stimulation and was dripped onto the bracket wire junction at a rate of $1 \mathrm{ml} / \mathrm{min}$ from a syringe.

Recently, modules coated with covalently bonded Metafasix (Super-Slick, TP Orthodontics, LaPorte, Ind) have been introduced claiming to reduce the friction of ligation by $60 \%$ compared with uncoated modules with similar elastic properties from the same manufacturer. Hence, the present 
study was taken up to evaluate different ligatures to make comparative evaluation of frictional resistance produced by Super Slick elastomeric ligature and other ligatures and to evaluate whether ligature material and type of ligation has any influence on the frictional resistance. Hain et $\mathrm{al}^{2}$ demonstrated that the new slick elastomeric modules from TP Orthodontics generated significantly less static friction at the module-archwire interface than do regular modules when tied normally. A figure 8 tie configuration significantly increased frictional resistance, but lubrication with human saliva produced a greater reduction in static friction with the slick modules than with regular modules tied in this way. Super Slick modules demonstrated a higher resistance to sliding when compared with conventional round crosssection module (Fig. 8). ${ }^{9}$

The manufacturers of Super Slick elastomeric modules claim that they become extremely slippery when wet or moistened in the oral environment. The highly lubricious surface has proven to reduce friction more than $70 \%$ during orthodontic treatment. ${ }^{7}$ But findings from the present study showed that Super Slick elastomeric modules produced highest coefficient of both static and kinetic friction with the conventional and figure-of- 8 ligation technique even in wet conditions using natural fresh human saliva.

\section{Limitations of the Study}

In the present study, single bracket-wire combination was used to study frictional resistance. However, in a clinical situation, wire may have to slide through multiple brackets.

Brackets with $0^{\circ}$ tip and $-7^{\circ}$ torque were used in our study. It would be better to use brackets with $0^{\circ}$ tip and $0^{\circ}$ torque to eliminate the effect of torque.

Present study was an in vitro study. Whatever care is taken to design an in vitro study it would be difficult to mimic in vivo situation.

In the present study, the modules were soaked in saliva for 10 minutes before testing and saliva was dripped at the rate of $1 \mathrm{ml}$ per minute at the site of interest during friction test. There are studies in which modules were soaked in saliva for 2 hours before testing and this may result in variation in frictional values.

\section{CONCLUSION}

All types of ligatures produced higher static and dynamic coefficient of friction as compared to self-ligating brackets.

All ligatures exhibited higher coefficient of both static and kinetic friction with figure-of-8 ligation as compared to conventional ligation method.

With all bracket, wire, ligature combinations coefficient of static friction was higher than the coefficient of kinetic friction.
Teflon-coated SS ligatures in SS brackets produced lowest frictional resistance while Super Slick elastomeric modules with full ceramic brackets produced highest frictional resistance.

Full ceramic brackets produced higher coefficient of both static and kinetic friction.

As Teflon-coated SS ligatures with conventional ligation produced the lowest coefficient of both static and kinetic coefficient of friction, they are the ligatures of choice for clinical application followed by SS ligatures.

Contrary to the claim made by the manufacturers of Super Slick elastomeric modules, they produced highest coefficient of both static and kinetic friction with the conventional and figure-of- 8 ligation technique.

\section{CLINICAL SIGNIFICANCES}

Contrary to the claim made by the manufacturers of Super Slick elastomeric modules, they produced highest coefficient of both static and kinetic friction with the conventional and figure-of-8 ligation technique.

\section{REFERENCES}

1. Kapila S, Sachdeva R. Mechanical properties and clinical applications of orthodontics wires. Am J Orthod Dentofac Orthop 1989Aug;96(2):100-109.

2. Hain M, Dhopatkar A, Rock P. The effect of ligation method on friction in sliding mechanics. Am J Orthod Dentofac Orthop 2003Apr;123(4):416-422.

3. Zachrisson BU, Buyukyilmaz T. Bonding in orthodontics. In: Thomas MG, Robert LV, Katherine WL, editors. Orthodontic current principles. 4th ed. Elsevier. p. 595.

4. Shih-Hsuan Chen S, Greenlee GM, Kim JE, Smith CL, Huang GJ. Systematic review of self-ligating brackets. Am J Orthod Dentofac Orthop 2010 Jun;137(6):726.e1-726.e18.

5. Throw R. Elastic ligatures, binding forces and anchorage taxation. Am J Orthod Dentofacial Orthod 1975 Jun;67(6): 694.

6. Sims AP, Waters NE, Birnie DJ, Pethybrige RJ. A comparison of the forces required to produce tooth movement in vitro using two self-ligating brackets and a pre-adjusted bracket employing two types of ligation. Eur J Orthod 1993 Oct;15(5):377-385.

7. TP Orthodontics product catalog. Super slick ligature ties. 2006.

8. Nishio C da, Motta AF, Elias CN, Mucha JN. In vitro evaluation of frictional forces between archwires and ceramic brackets. Am J Orthod Dentofac Orthop 2004 Jan;125(1):56-64.

9. Griffiths HS, Sherriff M, Ireland A J. Resistance to sliding with 3 types of elastomeric modules. Am J Orthod Dentofac Orthop 2005 Jun;127(6):670-675.

10. Rinchuse DJ, Miles PG. Self-ligating brackets: Present and future. Am J Orthod Dentofac Orthop 2007 Aug;132(2): 216-222.

11. Thorstenson GA, Kusy RP. Resistance to sliding of self-ligating brackets versus conventional stainless steel twin brackets with second-order angulation in the dry and wet (saliva) states. Am J Orthod Dentofac Orthop 2001 Oct;120(4):361-370. 
12. Shivapuja PK, Berger J. A comparative study of conventional ligation and self-ligating bracket systems. Am J Orthod Dentofac Orthop 1994 Nov;106(5):472-480.

13. De Franco DJ, Spiller RE, Fraunhofer JAV. Frictional resistances using Teflon-coated ligatures with various bracket-arch wire combinations. Angle Orthod 1995;65(1):63-74.

14. Bortoly TG. Sliding resistance with esthetic ligatures: An in-vitro study. Am J Orthod Dentofac Orthop 2008 Mar;133(3):340.e1-340.e7.

15. Khambay B, Millett D, McHugh S. Evaluation of methods of archwire ligation on frictional resistance. Eur J Orthod 2004 Jun;26(3):327-332.
16. Edwards GD, Davies EH, Jones SP. The ex vivo effect of ligation technique on the static frictional resistance of stainless steel brackets and arch wires. Br J Orthod 1995 May;22(2): 145-53.

17. Kusy RP, Whitley JQ. Frictional resistances of metal-lined ceramic brackets versus conventional stainless steel brackets and development of 3-D friction maps. Angle Orthod 2001 Oct; 71(5):364-374.

18. Baker KL, Neiberg LG, Weimer AD, Hanna M. Frictional changes in force values caused by saliva substitution. Am J Orthod Dentofacial Orthop 1987 Apr;91(4):316-320. 